\title{
Pipette Method: Errors Resulting From Aliquot Collection Depth in Soil Clay Quantification
}

\author{
Jaedson Cláudio Anunciato Mota ${ }^{1}$, Carlos Eduardo Linhares Feitosa ${ }^{2}$, Lucas de Sousa Oliveira ${ }^{1}$, \\ José Israel Pinheiro ${ }^{1}$, Alfredo Mendonça de Sousa ${ }^{1}$, Thiago Leite de Alencar ${ }^{3}$, Márcio Godofrêdo Rocha Lobato ${ }^{1}$, \\ Alexandre dos Santos Queiroz ${ }^{1} \&$ Ícaro Vasconcelos do Nascimento ${ }^{1}$ \\ ${ }^{1}$ Universidade Federal do Ceará, Fortaleza, Ceará, Brazil \\ ${ }^{2}$ Universidade Federal do Rio Grande do Sul, Rio Grande do Sul, Brazil \\ ${ }^{3}$ Instituto Federal de Educação, Ciência e Tecnologia do Piauí, Piauí, Brazil \\ Correspondence: Lucas de Sousa Oliveira, Universidade Federal do Ceará, Fortaleza, Ceará, Brazil. E-mail: \\ lucasdesousa@alu.ufc.br
}

Received: September 19, 2018

Accepted: November 5, $2018 \quad$ Online Published: January 15, 2019

doi:10.5539/jas.v11n2p244

URL: https://doi.org/10.5539/jas.v11n2p244

\begin{abstract}
Granulometry represents the relative proportions of the fractions that compose the soil, being an important agronomic tool to infer mean values of density, water availability and cation exchange capacity, besides being useful in soil classification. Among the methods employed to determine the fractions composing the soil, those which consider the separation by sedimentation for the clay fraction still have problems in the analytical protocol, which are directly responsible of errors in the results obtained. Given the above, this study aimed to evaluate the best pipette immersion depth to collect the aliquot containing only clay, to calculate and discuss the errors associated with collection of the aliquot containing clay fraction in soil granulometric analysis. Samples for granulometric analysis were collected in the superficial layer and top of the B horizon of an Argissolo Amarelo, corresponding to the textural classes sandy loam and sandy clay. Regardless of soil textural class, the depth $h=5$ $\mathrm{cm}$ established in the calculation using the Stokes's equation leads to overestimation and underestimation of clay and silt fractions in the soil. The collection should be performed with the pipette tip positioned at $h / 2=2.5 \mathrm{~cm}$.
\end{abstract}

Keywords: soil physics, granulometric analysis, Stokes's law

\section{Introduction}

Granulometry represents the relative proportions of the fractions that compose the soil. In most cases, it is a reference to the quantities of sand, silt and clay, fractions which are not changed by soil use and management, because they result from pedogenetic processes. It has great agronomic importance because, based on it, it is possible to infer mean values of density (Sivarajan et al., 2018), water availability (Rabot et al., 2018) and cation exchange capacity, besides being useful in soil classification (Klein et al., 2013). Regarding laboratory protocols, there is a great variety of techniques in soil granulometric analysis, and approximately four hundred methods are known nowadays (Almeida, 2008). Among the most widely known methods, two deserve special attention for being the most commonly used: the pipette method (Robinson, 1922) and the hydrometer method (Bouyoucos, 1927).

Soil granulometric analysis is normally carried out in three steps: application of pretreatments to remove flocculating and cementing agents, sample dispersion, and quantification of fractions (Ruiz, 2005). The first step aims to remove organic matter, iron oxides, carbonates and soluble salts (Ruiz, 2005). Soil sample dispersion is conducted by using a combination of chemical processes and mechanical disaggregation (Durner et al., 2017). Sieving is used for the sand fraction and sedimentation for the smaller particles - silt and clay (Cunha et al., 2014b).

For the sand fraction, separation by sieving leads to results with better precision and accuracy; however, separation by sedimentation for silt and clay fractions still has several problems in the various methods used in the analytical protocol, which are directly responsible of errors contained in the results obtained in the measurement of these granulometric fractions (Durner et al., 2017). Incomplete dispersion of soil particles, associated with the inefficiency of the procedures used, leads to errors in the quantification of the clay fraction 
and, consequently, of silt and sand fractions (Cunha et al., 2014b). These experimental errors, depending on the magnitude, may cause serious consequences for the utilization of the soil granulometric analysis results, from the simplest applications, directly related to soil use and management, to the more complex ones, which involve the modelling of soil physical, chemical, biological and mechanical processes (Corá et al., 2009).

Pipette method is also one of the main methods used to determine clay content. The method is frequently used due to the technical impossibility of manufacturing sieves with adequate diameters for the dimensions of these particles (Dias, 2004). It is worth highlighting that clay particles in the soil exhibit a laminar shape and the mesh opening in sieve manufacturing considers the equivalent diameter of spherical particles. Thus, contents of clay particles in the soil are usually determined using a method that is based on the sedimentation velocity of the particles. The principle of this method is the quantification of clay content based on the weighing of samples, collected at a certain depth in aqueous medium within a given time of sedimentation. Among its limitations, special attention should be paid to the collection depth established in the calculations using the Stokes's law, a factor that leads to errors in the determination of clay contents by this method (Dias, 2004; Durner et al., 2017).

In this context, the hypothesis tested in the present study is that the aliquot collected at the depth $h$ established in the calculation by the Stokes's law, leads to overestimation of soil clay fraction because sit also contains silt. Therefore, the objectives were to: i) define the best depth for pipette immersion to collect the aliquot containing only clay; and ii) calculate and discuss the errors associated with the collection of the aliquot containing the clay fraction.

\section{Method and Methods}

\subsection{Experimental Site}

To perform soil granulometric analysis, samples were collected at the Federal University of Ceará, Campus of Pici, in the upper layer $(0-5 \mathrm{~cm})$ and from the first $5 \mathrm{~cm}$ of the B horizon (in both situations, in the first five centimeters) of a Argissolo Amarelo (Embrapa, 2013), corresponding sandy loam and sandy clay textures, respectively (Santos et al., 2013). All analyses were carried out at the Soil Physics Laboratory of the Soil Sciences Department in the Federal University of Ceará.

\subsection{Pipette Immersion Depths for Aliquot Collection in the Quantification of Clay Fraction}

For each treatment 10 samples of oven-dried fine earth (ODFE) weighing $20 \mathrm{~g}$ were used. Each sample was put in a $250 \mathrm{~mL}$ beaker to which $100 \mathrm{~mL}$ of distilled water and $10 \mathrm{~mL}$ of o $1 \mathrm{~mol} \mathrm{~L}^{-1}$ sodium hydroxide, a chemical dispersant, were added. The mixture was allowed to rest for 12 to 16 hours for chemical dispersion of particles. Following that, physical dispersion was carried out in vertical shaker at $12.000 \mathrm{rpm}$ for $5 \mathrm{~min}$ for the sandy loam material, and $10 \mathrm{~min}$ for the sandy clay one. Subsequently, sands were separated in a sieve with $0.053 \mathrm{~mm}$ mesh. The filtrate, composed of clay and silt, was collected in a $1 \mathrm{~L}$ sedimentation cylinder. The cylinder volume was topped up with distilled water, and the suspension was agitated for homogenization per 20 seconds (Gee \& Or, 2002).

According to the Stokes's law, the $5 \mathrm{~cm}$ depth containing only the clay fraction in suspension was considered. After the time of sedimentation, three procedures were used to collect the $25 \mathrm{~mL}$ aliquot containing clay notably (i) by suction, immersing the pipette tip to 2.5 and $5 \mathrm{~cm}$ depths from the liquid surface, (ii) by suction, immersing the pipette tip to 2.5 and $5 \mathrm{~cm}$ depths from the liquid surface, and (iii) by siphoning of solution containing clay + dispersant using a drain installed on the side of the sedimentation cylinder at $5 \mathrm{~cm}$ from the $1 \mathrm{~L}$ mark. (25 mL were collected from the drained volume. An illustration of the apparatus individually used in each treatment is presented in Figure 1. 


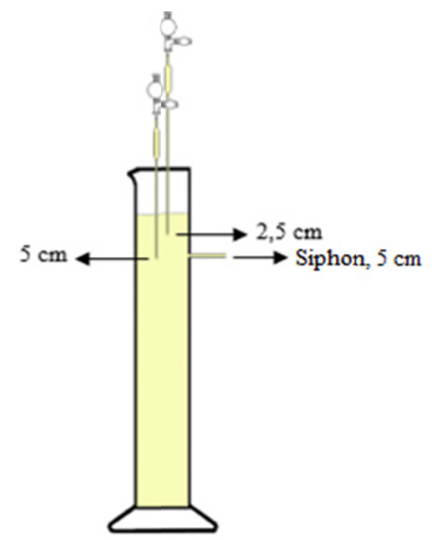

Figure 1. Detail of the pipettes and drain to collect the aliquot containing clay

The siphoning procedure was taken as reference because there is no risk of containing silt, as in the protocol by suction, when the pipette tip is immersed at the depth $h$, used to calculate sedimentation time by the Stokes's law. The aliquot was transferred to a $30 \mathrm{~mL}$ beaker and dried in the oven at $105^{\circ} \mathrm{C}$, until constant weight to determine the weight of the clay fraction + dispersant. A blank control was used to determine the dispersant weight in the aliquot collected. Equation 1 was used to determine clay percentage:

$$
\left.\frac{b}{E}\right) \times 100
$$

where, $V t$ was the total volume $(50 \mathrm{~mL}), V p$ was the pipetted volume $(2.5 \mathrm{~mL}), W c$ was the oven-dried weight of clay in $2.5 \mathrm{~mL}$ of suspension (g); $W b$ was the oven-dried weight $\left(105^{\circ} \mathrm{C}\right)$ of the blank in $2.5 \mathrm{~mL}$ of this solution (g); and $W_{O D F E}$ was the weight (g) of oven-dried fine earth.

\subsection{Statistical Design and Error Analysis}

For each soil texture, the experiment of granulometric analysis (methods to collect the aliquot containing clay) was conducted in a completely randomized design, in $2 \times 3$ factorial scheme (two textures: sandy and clayey; three procedures to collect the aliquot containing clay + dispersant including (i) suction with pipette tip at $2.5 \mathrm{~cm}$ depth from the aqueous suspension surface, (ii) suction with pipette tip at $5 \mathrm{~cm}$ depth from the aqueous suspension surface, and (iii) siphoning, though a drain installed on the side of the sedimentation cylinder $5 \mathrm{~cm}$ from the $1 \mathrm{~L}$ mark.

\subsection{Data Analysis}

Analysis of variance was carried out for the collection methods and the soil textural class as well. Mean values of clay content were compared using Tukey tests at $5 \%$ probability. The analyses were carried out using the statistical program Assistat (Silva \& Azevedo, 2016). The relative difference between the proposed treatments and the reference to quantify the clay fraction was calculated using Equation 2:

$$
\times 100
$$

\section{Results and Discussion}

The analysis of variance revealed highly significant difference $(p=0.01)$ between the two soil textural classes as well as and between the aliquot collection methods but did not show interaction between soil textural class and aliquot collection method (Table 1). 
Table 1. Analysis of variance for soil fractions considering the methods to collect the aliquot containing clay in two soil textural classes

\begin{tabular}{|c|c|c|c|c|c|c|c|}
\hline \multirow{2}{*}{ Source of variation } & \multirow{2}{*}{ DF } & \multicolumn{2}{|c|}{ Clay fraction } & \multicolumn{2}{|c|}{ Silt fraction } & \multicolumn{2}{|c|}{ Sand fraction } \\
\hline & & Mean squares & $\mathrm{F}$ & Mean squares & $\mathrm{F}$ & Mean squares & F \\
\hline Soil textures (F1) & 1 & 836698.24 & $30311.11^{* *}$ & 1552.86 & $41.26^{* *}$ & 910349.47 & $30981.60^{* *}$ \\
\hline Clay collection methods (F2) & 2 & 765.51 & $27.73^{* *}$ & 1042.54 & $27.70^{* *}$ & 41.70 & $1.42^{\mathrm{ns}}$ \\
\hline Interaction $\mathrm{F} 1 \mathrm{xF} 2$ & 2 & 17.21 & $0.62^{\mathrm{ns}}$ & 182.77 & $4.86^{* *}$ & 147.83 & $5.03^{* *}$ \\
\hline Treatments & 5 & 167652.74 & $6073.57^{* *}$ & 800.69 & $21.28^{* *}$ & 182145.71 & $6198.90^{* *}$ \\
\hline Residual & 54 & 27.60 & & 37.63 & & 29.38 & \\
\hline Coefficient of Variation & & $2 \%$ & & $12 \%$ & & $1 \%$ & \\
\hline
\end{tabular}

Note. DF: degrees of freedom.

According to the results in Figures 2(a) and 2(b), the mean clay contents $\left(\mathrm{g} \mathrm{kg}^{-1}\right)$ in both textural classes were statistically higher in the clay collection method with a pipette at $h=5 \mathrm{~cm}$ than those obtained in the methods of siphoning and collection at $h=2.5 \mathrm{~cm}$, corroborating the hypothesis previously presented in the present study.
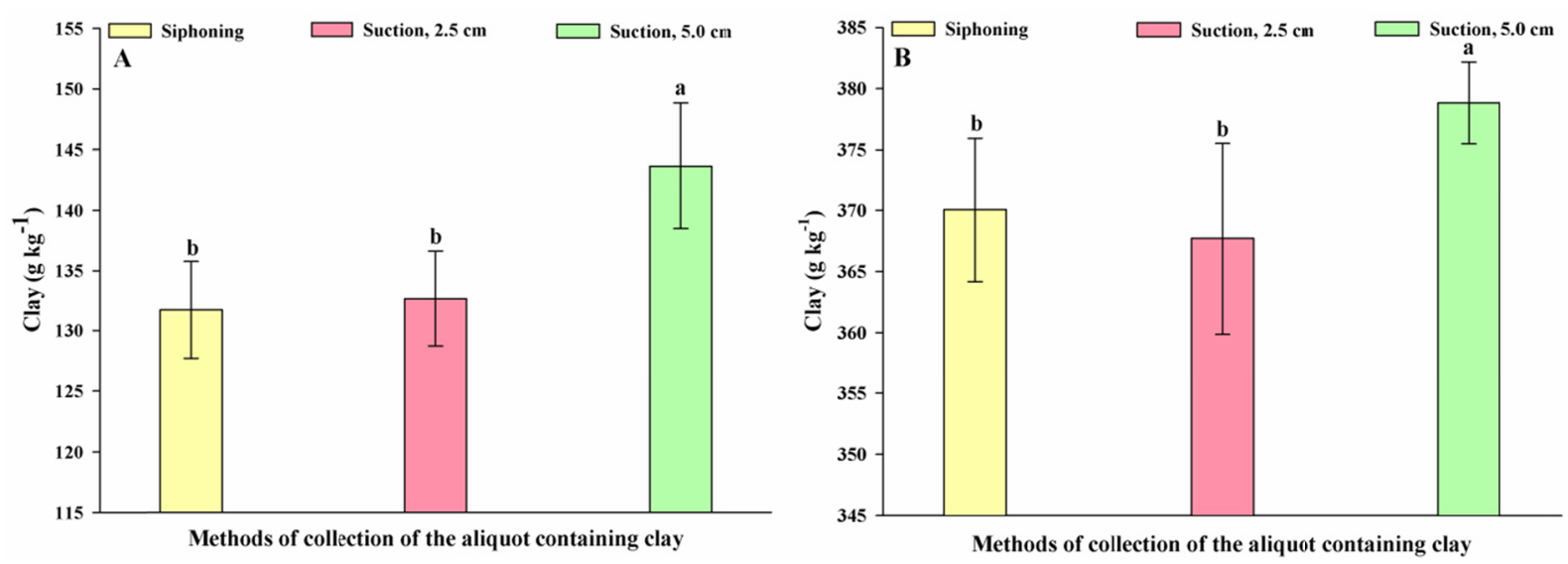

Figure 2. Mean values of clay by the methods of collection of the aliquot containing clay

( $\mathrm{A}=$ sandy loam; $\mathrm{B}=$ sandy clay)

Note. Means followed by the same letter do not differ statistically according to the Tukey test at $5 \%$ probability.

It is important to point out that, considering the Stokes's law-knowing the limitations of its use in the sedimentation of soil particles - the depth $h$ only ensures that at that point, and at that time, the particles precipitated are the ones with equivalent diameter larger than that of the particles to be determined (Gee \& Or, 2002). Considering the interest in quantifying the clay fraction (with equivalent diameter $\leq 2 \mu \mathrm{m}$ ), at the depth $h$, for a certain time $t$ dependent on temperature, particles with equivalent diameter immediately larger than 2 $\mu \mathrm{m}$-silt are assumed to settle at the bottom. However, it has been demonstrated that the aqueous solution should not be collected with the pipette positioned at the depth $h=5 \mathrm{~cm}$ because, as shown (Figure 1), the silt fraction is also collected along with the clay fraction.

The explanation for the presence of clay and silt—instead of only clay-when the solution is collected with the pipette tip at depth $h=5 \mathrm{~cm}$ comes from a simple analysis of the collection of the aliquot containing the aqueous solution. Based on Figure 3, in the collection a manual or automatic pipettor is attached to the opposite end of the pipette tip. 


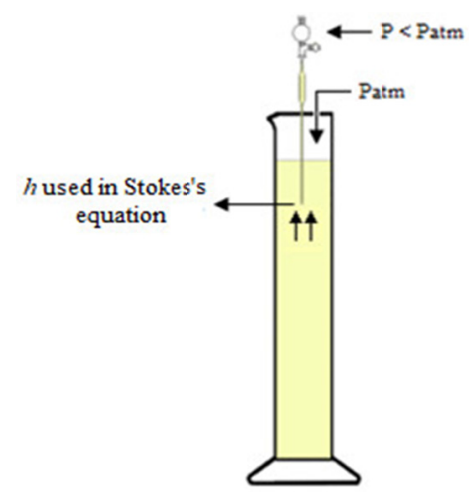

Figure 3. Detail of the pressures involved in the aqueous solution collection

When the analyst immerses the pipette tip up to the depth $h=5 \mathrm{~cm}$ and presses it, the internal pressure of the pipettor + pipette set becomes lower than the atmospheric pressure and the aqueous solution is naturally pushed into the pipette. It occurs that, when the atmospheric pressure pushes the liquid column $h$, it causes silt, which is immediately below $h$, to enter the pipette as well. Further, when the manual or automatic pipettor is immersed at depth $h$, there is a displacement in the fluid volume because the device is denser. Since the depth $h$ is considered as the limit to quantify the clay fraction, any alteration causing displacement in the fluid volume leads to discrepancy in the values obtained to represent this granulometric fraction.

Consequently, the aliquot containing the aqueous solution will contain silt and clay particles, which is not consistent with soil clay content. Thus, to prevent silt from being counted as clay, the pipette tip needs to be contained within the column $h$-preferably in the center-and not at the depth $h$ used to calculate sedimentation time by the Stokes's law.

Regarding the relative difference, for the sandy texture the protocol with suction at $h=2.5 \mathrm{~cm}$ leads to insignificant underestimation of the clay fraction, $-0.3 \%$, whereas the protocol with suction at $h=5 \mathrm{~cm}$ overestimates the clay fraction by $4.1 \%$. In relation to the clayey textural class, there were underestimation of $-0.6 \%$ and overestimation of $2.4 \%$, respectively, for both protocols mentioned above.

The analysis of variance revealed high significant difference in the silt fraction for both soil textural classes, due to the methods of clay fraction collection, as well as the interaction between both sources of variation (Table 1). For the sandy loam texture, the mean values of silt did not differ between the methods of siphoning and suction at $h=2.5 \mathrm{~cm}$, although in the latter the silt values were statistically similar to those observed in the protocol with suction at $h=5 \mathrm{~cm}$. In this textural class, the siphoning method statistically differed from the method of collection at $h=5 \mathrm{~cm}$, which showed lower mean values of silt (Figure 4a). There was no significant difference between the methods of collection by siphoning and suction at $h=2.5 \mathrm{~cm}$ in the soil with sandy clay texture (Figure 4b). 

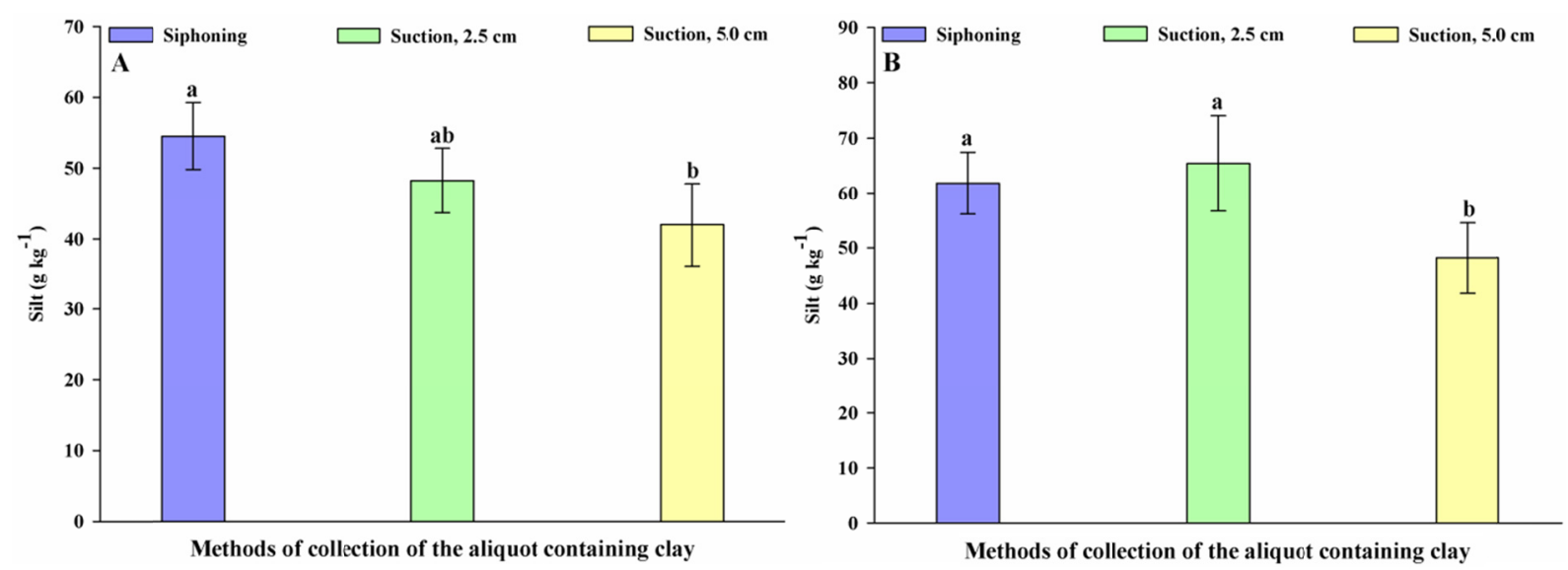

Figure 4. Mean values of silt obtained by the methods of collection of the aliquot containing clay ( $\mathrm{A}=$ sandy loam; $\mathrm{B}=$ sandy clay)

Note. Means followed by the same letter do not differ statistically according to the Tukey test at $5 \%$ probability.

In all the situations, it was demonstrated that the aliquot containing clay collected at $h=5 \mathrm{~cm}$ also contains silt, which is the reason why the silt fraction was significantly underestimated compared with the value obtained in the siphoning protocol.

Some analysis protocols suggest that the proportion of silt should be defined by subtraction from the other fractions (clay and sand) in relation to the original sample (Ruiz, 2005). According to these authors, in the estimation of the sedimentation time of the silt fraction, a more accurate form to quantify this fraction is to consider the Law of Stokes (Stokes, 1851), making a few assumptions - for instance, that the forms of the fractions composing the soil are not only spherical and that, in the sedimentation for granulometric analysis, the sediments have a uniform displacement velocity, with a straight-line trajectory, thus avoiding turbulence during the process. It is worth highlighting that the temperature should also remain constant during the analysis, because sedimentation velocity is inversely proportional to fluid viscosity. Therefore, oscillations in the temperature of the environment during the process lead to changes in fluid viscosity and, consequently, in the sedimentation velocity of the particles. The authors concluded that some mathematical determinations lead to more accurate results in the granulometric analysis, also reducing the silt/clay ratios, used as criteria in soil characterization and classification.

Regarding the sand fraction, the analysis of variance showed significant effect of the soil textural classes and of the interaction between soil textural classes and clay fraction collection methods but did not detect significant difference between clay fraction collection methods (Table 1).

Since the sand fraction was separated by sieving in the experimental procedure, it was not expected to differ regardless of the protocol for clay fraction collection, a fact confirmed in the analysis of variance. According to Ruiz (2005), the separation by sieving provides more accurate and reliable results, but soil sample dispersion is fundamental to maintain the accuracy, which requires a good combination of the chemical processes and mechanical disaggregation.

\section{Conclusion}

Regardless of soil textural class, the aliquot collected at the depth $h=5 \mathrm{~cm}$ established in the calculation by the Stokes's equation leads to overestimation of the clay fraction and to underestimation of silt fraction in the soil. The collection should be carried out with the pipette tip positioned at $h / 2=2.5 \mathrm{~cm}$.

\section{References}

Almeida, B. G. (2008). Métodos alternativos de determinação de parâmetros físicos do solo e uso de condicionadores químicos no estudo da qualidade do solo (Dissertação, Escola Superior de Agronomia Luiz de Queiroz, Piracicaba). https://doi.org/10.11606/T.11.2008.tde-18112008-100808

Bouyoucos, G. J. (1927). The hydrometer as a new method for the mechanical analysis of soils. Soil Science, 23, 343-352. https://doi.org/10.1097/00010694-192705000-00002 
Corá, J. E., Fernandes, C., Beraldo, J. M. G., \& Marcelo, A. V. (2009). Adição de areia para a dispersão de solos na análise granulométrica. Revista Brasileira de Ciência do Solo, 33, 255-262. https://doi.org/10.1590/S010 0-06832009000200003

Cunha, J. C., Freire, M. B. G. S., Ruiz, H. A., Fernandes, R. B. A., \& Alvarez, V. H. (2014). Comparação de dispersantes químicos na análise granulométrica de solos do Estado do Pernambuco. Revista Brasileira de Engenharia Agrícola e Ambiental, 18, 783-789. https://doi.org/10.1590/1807-1929/agriambi.v18n08p783789

Dias, J. A. (2004). A análise sedimentar e o conhecimento dos sistemas marinhos (p. 90). Universidade do Algarve.

Durner, W., Iden S. C., \& von Unold, G. (2017). The integral suspension pressure method (ISP) for precise particle-size analysis by gravitational sedimentation. Water Resources Research, 53, 33-48. https://doi.org/ 10.1002/2016WR019830

Embrapa. (2013). Sistema Brasileiro de Classificação de Solos (3rd ed.). Brasília, Brazil.

Gee, G. W., \& Or, D. (2002). Particle-size analysis. In J. H. Dane, \& G. C. Topp (Eds.), Methods of soil analysis (3rd ed., pp. 255-293), Physical methods (Book Series, 5). Madison: Soil Science Society of America.

Klein, V. A., Madalosso, T., Reichert, J. M., Suzuki, L. E. A. S., Veiga, M., Albuquerque, J. A., \& Pauletto, E. A. (2013). Metodologias de controle de qualidade de análises granulométricas do solo. Ciência Rural, 43, 850-853. https://doi.org/10.1590/S0103-84782013000500015

Rabot, E., Wiesmeier, M., Schlüter, S., \& Vogel, H. J. (2018). Soil structure as an indicator of soil functions: A review. Geoderma, 314, 122-137. https://doi.org/10.1016/j.geoderma.2017.11.009

Robinson, G. W. (1922). A new method for the mechanical analysis of soils and other dispersions. The Journal of Agricultural Science, 12, 306-321. https://doi.org/10.1017/S0021859600005360

Ruiz, H. A. (2005). Incremento da exatidão da análise granulométrica do solo por meio da coleta da suspensão (silte + argila). Revista Brasileira de Ciência do Solo, 29, 297-300. https://doi.org/10.1590/S0100-0683200 5000200015

Santos, R. D., Lemos, R. C., Santos, H. G., Ker, J. C., Anjos, L. H. C., \& Shimizu, S. H. (2013). Manual de descrição e coleta de solos no campo (p. 100). Viçosa, MG, Sociedade Brasileira de Ciência do Solo.

Silva, F. A. S., \& Azevedo, C. A. V. (2016). The Assistat Software Version 7.7 and its use in the analysis of experimental data. African Journal Agricultural Research, 11(39), 3733-3740. https://doi:105897/AJAR20 16.11522

Sivarajan, S., Maharlooei, M., Bajawa, S. G., \& Nowatzki, J. (2018). Impact of soil compaction due to wheel traffic on corn and soybean growth, development and yield. Soil and Tillage, 4, 230-236. https://doi.org/ 10.1016/j.still.2017.09.001

Stokes, G. G. (1851). On the effect of the internal friction of fluids on the motion of pendulums. Transaction of the Cambridge Philosophical Society, 9, 8-106.

\section{Copyrights}

Copyright for this article is retained by the author(s), with first publication rights granted to the journal.

This is an open-access article distributed under the terms and conditions of the Creative Commons Attribution license (http://creativecommons.org/licenses/by/4.0/). 